\title{
Environmental Factors in Renal Disease: The Contribution of Urinary Tract Infections in Nigerian Renal Disease Burden-Research and Minireview
}

Tobias I Ndubuisi Ezejiofor ${ }^{*}$

Department of Biotechnology, School of Biological Sciences, Federal University of Technology, P.M.B 1526, Owerri, Nigeria

*Corresponding author: Tobias I Ndubuisi Ezejiofor, Department of Biotechnology, School of Biological Sciences, Federal University of Technology, P.M.B 1526, Owerri, Nigeria, Tel: +2348036774598; E-mail: tinezejiofor@gmail.com

Received date: November 18, 2015; Accepted date: February 27, 2016; Published date: March 04, 2016

Copyright: () 2016 Ezejiofor TIN. This is an open-access article distributed under the terms of the Creative Commons Attribution License, which permits unrestricted use, distribution, and reproduction in any medium, provided the original author and source are credited.

\begin{abstract}
Background: Asymptomatic and mild nature of urinary tract infections (UTIS) make them underrated, overlooked but dangerous, because they are prelude to most renal diseases. Like asymptomatic UTIs, some renal diseases are symptomless until they have reached advanced stage, making their victims easily vulnerable to complications before actual diagnosis of renal disease may be made. This study was aimed at surveying the environmental factors responsible for the renal disease burden of Nigeria with a particular focus on the contributions of UTIs.
\end{abstract}

Method: Urine samples from renal disease patients of the University of Nigeria teaching hospital (UNTH), Enugu, Nigeria were analyzed for bacteriuria using standard microbiological procedures.

Results: An overall incidence of $28 \%$ bacteriuria was obtained, based on the criterion of significant bacteriuria (> $10^{5}$ colonies $/ \mathrm{ml}$ ). While fungal yeasts, Candida albicans contributed $30 \%$, various bacterial species jointly accounted for $70 \%$ of the entire microbial agents responsible for UTIs among the subjects. Subsequent Gram's, microscopy and biochemical characterization tests revealed seven bacterial species viz Escherichia coli $(29 \%)$, Klebsiella spp (22\%), Proteus mirabilis (14\%), Pseudomonas aeruginosa (7\%), Streptococcus faecalis $(7 \%)$, Staphylococcus aureus $(7 \%)$ and Staphylococcus epidermidis (14\%). Gender distribution of the isolates showed that $S$. aureus was isolated from the males while E. coli, Proteus mirabilis, Streptococcus faecalis and Pseudomonas aeruginosa from the females; Klebsiella spp was isolated from the males (33\%) and females $(67 \%)$ respectively, while S. epidermidis was isolated equally $(50 \%)$ from both sexes. Adoption of leucocytes' presence in urine as part of diagnostic criteria revealed significant bacteriuria with significant pyuria $(21 \%)$, significant pyuria without significant bacteriuria $(52 \%)$, and significant bacteriuria without significant pyuria $(7 \%)$, no significant bacteriuria without significant pyuria $(20 \%)$. Also, urinalyses gave proteinuria $(84 \%)$, haematuria $(45 \%)$ and glycosuria $(6 \%)$.

Conclusions: The study revealed an overall incidence of $28 \%$ bacteriuria. Though UTIs by sundry bacterial organisms and fungal yeast cells, Candida albicans made reckonable contributions to the renal disease load of UNTH, Enugu, additional evidence from urinalyses revealing proteinuria, glycosuria and haematuria, etc., suggest that apart from the UTIs, diabetes mellitus and/or urinary schistosomiasis (possibly accounting for the haematuria) are part of the diseases complex defined by yet-to-be identified factors (possibly including chemical entities) in our environment that determine the burden and patterns of renal diseases profile of Nigeria. Further search is thus warranted.

Keywords: Environmental factors; UTIs; Renal diseases burden; Epidemiology; Public health implication, Nigeria

\section{Background}

Evidence shows there has been a considerable rise in the incidence of renal diseases in Nigeria in the last three decades. A survey by this author (unpublished) showed there was a 265\% rise between 1984 and 1993 based on records from the University of Nigeria Teaching Hospital, Enugu, Nigeria, and that trend has remained consistently so ever since then as confirmed in recent studies [1-4]. This rising trend appears to be assuming a global dimension, as chronic kidney disease (CKD) has become a burden of health care globally $[5,6]$ with more disease seen in men than women [6]. Though factors responsible for this rising trend has not been clearly documented, known risk factors for renal disease such as hypertension, diabetes mellitus, drugs, food poisoning and other environmentally-related toxicities, as well as urinary tract infections affect significant proportion of our population $[7,4]$. Urinary tract infection (UTI) is described as the presence of microorganism in the urinary tract $[8,9]$, or an infection of the urinary tract that encompasses a wide variety of clinical entities whose common denominator is microbial invasion of any of the tissues of the tract extending from the renal cortex to urethral meatus [10]. It is an infection of one or more components of the urinary tract consisting of two kidneys, two ureters, a bladder, and a urethra. Thus, UTIs refer to the presence of microbial pathogens within the urinary tract and it is usually classified by the site of infection as bladder (cystitis), kidney (pyelonephritis) or urine (bacteriuria) [9]. Infections are caused by microbes-organisms too small to be seen without a microscope-including fungi, viruses, and bacteria. However, bacteria are the most common cause of UTIs. Urinary tract infection (UTI) remains the most common bacterial infection in human population and is also one of the most frequently occurring nosocomial infections [11]. Its annual global incidence is of almost 250 million [12,13]. 
The urinary tract is the body's drainage system for removing wastes and extra water. The urinary tract includes two kidneys, two ureters, a bladder, and a urethra. The kidneys are a pair of bean-shaped organs, each about the size of a fist and located below the ribs, one on each side of the spine, toward the middle of the back. They filter waste out of the blood and produce urine to carry the wastes and excess water out of the body. The urine is carried from the kidneys, through the ureters, and into the bladder. The bladder is a hollow muscular organ that stores urine for a short period. It stretches as urine accumulates and, at a certain point, it signals the body to relieve the growing pressure. A muscular sphincter valve at the opening of the bladder is relaxed and the bladder contracts to send urine through the urethra and out of the body [14-16].

Urine does not normally contain microorganisms, but if it is obstructed from leaving the body or retained in the bladder, it provides a good environment for bacteria to grow. Most urinary tract infections are due to bacteria that are introduced into the opening of the urethra. They stick to the walls of the urethra, multiplying and moving up the urethra to the bladder. Normally, bacteria that enter the urinary tract are rapidly removed by the body before they cause symptoms. However, sometimes bacteria overcome the body's natural defenses and cause infection. The blanket term UTI is frequently used, but a urinary tract infection may also be identified by the part of the urinary tract affected. Hence, urethritis is an inflammation and/or infection of the urethra, while bladder involvement is called cystitis. Bacteria may travel up the ureters to multiply and infect the kidneys, so, when one or both kidneys are inflamed or infected, it is called pyelonephritis $[9,15,16]$.

Most UTIs remain in the lower urinary tract (urethra or bladder) where they cause symptoms such as urinary urgency and a burning sensation during urination. Most of these infections are considered uncomplicated and are easily treated, but if they are not addressed, the infection may spread up through the ureters and into the kidneys. A kidney infection is more dangerous and can lead to permanent kidney damage. In some cases, a urinary tract infection may lead to an infection in the bloodstream (sepsis, septicaemia) that can be lifethreatening. Rarely does a bloodstream infection infect the kidneys. Although a variety of bacteria can cause UTIs, most are due to Escherichia coli, a bacterium that is common in the gastrointestinal tract and is routinely found in stool $[9,17,18]$. Other bacteria that may cause UTIs include species of: Proteus, Klebsiella, Enterococcus and Staphylococcus $[17,18]$. Although occasionally, a UTI may be due to yeasts such as Candida albicans [19], urethritis is often due to a sexually transmitted disease such as herpes, Chlamydia, or gonorrhea [14].

\section{Urinary tract infections: Socio-economic and risk factors}

There are important medical and financial implications associated with UTI. Urinary tract infections are among the most common infectious diseases and contribute to high financial burden worldwide [20]. In spite of the difficulties in assessing the incidence of UTI (because they are not reportable diseases), UTIs remain a significant cause of morbidity and health care expenditure in persons of all ages. They are considered to be the most common bacterial infection as they accounted for very high proportion of office and emergency visits as well as hospitalization [21]. According to the American Urological Association Foundation, UTIs result in more than 7 million visits to doctor's offices a year and more than 1million hospitalizations. Financially, the estimated annual cost of community acquired UTI is significant [22], put at approximately $\$ 1.6$ billion $[21,23,24]$. Although in the non-obstructed, non-pregnant adult female, acute uncomplicated UTI is believed to be a benign illness with no long-term medical consequences, UTI elevates the risk of Pyelonephritis, premature delivery, and foetal mortality among pregnant women, and is associated with impaired renal function and end-stage renal diseases among paediatric patients.

Recent studies however, have helped to define the population groups at risk as well as the most cost-effective strategies. Although they can affect anyone at any age, women are much more likely than men to have a UTI, with about $40 \%$ of women compared to $12 \%$ of men having at least one in their lifetime, while nearly 1 in 3 women will have had at least 1 episode of UTI requiring antimicrobial therapy by the age of 24 years $[14,18,21,23,25]$. Urinary Tract Infection is more common among women than men because of their special physical structure. It is thought that a woman's increased susceptibility is partly anatomical, because the woman's urethra is shorter and because their anus and vagina are relatively close to the urethra. Apart from anatomy, a woman's propensity to develop UTIs has also been explained on the basis of other certain behavioural factors, including delays in micturition, sexual activity and the use of diaphragm and spermicidal agents (both of which promote colonization of periurethral area with coliform bacteria)[26].

Although sexually active young women are disproportionately affected, several other populations at increased risk of UTI include infants, pregnant women, the elderly, and other patients with sundry health conditions such as diabetes[14-16,21,22,27-33], multiple sclerosis, rheumatoid arthritis [14-16,21,34] AIDS/HIV, HIV-Malaria co-infection[14-17,21,31], underlying urologic anatomical abnormalities (e.g. narrowing of the urethra or ureters), genitorurinary instrumentation [14-16,21,32-36], spinal cord injuries [36,37], urine retention, vesicoureteral reflux [38-42], enlarged prostate (may inhibit urine flow in men)[43,44], kidney stones/kidney disease [16,45], Kidney transplant/allograft rejection[32,46,47], sickle cell disease and any condition that suppresses the immune system including Vitamin D deficiency $[3,4,29,44,48]$. Other factors of reckoning in UTI include age and parity [49]. Co-infection with urinary schistomiasis has also been noted as increase risk factor for UTI, as high prevalence of bacteriuria co-infection has been noted among children with urinary schistosomiasis caused by schistosoma haematobium [50-52] with haematuria and proteinuria serving as diagnostic indicator in an endemic rural community [53]. Urinary tuberculosis is another potential risk factor, since this is associated with the development of urothelial carcinoma (but not renal cell carcinoma) [44], thus impinging on normal urine flow. In fact, anything that slows down the passage of the urine, blocks it, or introduces bacteria into the urinary tract can raise a person's risk of having a UTI as is the case in those undergoing genitourinary instrumentation or catheterization [21,23,32,34-36]. Catheterassociated UTI is the most common nosocomial infection accounting for >1million cases in hospitals and nursing homes; the risk of UTI increases with increasing duration of Catheterization. In noninstitutionalized elderly population, UTIs are the second most common form of infection, accounting for nearly $25 \%$ of all infections.

\section{Urinary tract infections: signs, symptoms, and complications}

Although UTI symptoms vary, many people will experience some discomforts which include: a strong, frequently persistent urge or desire to urinate, but not much urine coming out when you do, a Pain 
and burning sensation during urination, cloudy, strong-smelling urine, and possibly Pain in the pelvic area (or lower back). Those with UTIs may also experience discomfort or pressure in the lower abdomen, and small amounts of blood in the urine. If the UTI is more severe and/or has spread into the kidneys, it may cause flank pain, high fever, shaking, chills, nausea or vomiting. Fevers are also seen when the infection spreads into the blood (sepsis). Some people may also experience mental changes and confusion with a UTI, while others may not have any symptoms at all. In a study of UTI in febrile under five children in Enugu, South Eastern Nigeria with a view to relating it to demographic and clinical characteristics, Ibeneme et al. [54] observed the common clinical features among these children to include vomiting, abdominal pain, diarrhea, urinary frequency and urgency, but noted however that none of these had a significant association with UTI. Baracco and Mattoo, [40] observed that in febrile newborns, particularly those born prematurely and with a low birth weight, UTI is the most common bacterial infection, and half of the neonates with UTI may have only low-grade fever or no fever, while Jaundice in the absence of any other symptoms or signs may be the only clinical manifestation of UTI in neonates.

Initially, a UTI should be categorized as uncomplicated or complicated. Uncomplicated UTIs are those that occur in a normal genitourinary tract with no prior instrumentation, whereas complicated infections are diagnosed in genitourinary tracts that have structural or functional abnormalities including instrumentation such as indwelling urethral catheters, and are frequently asymptomatic. In most cases, UTIs are acute and uncomplicated. They are treated and the symptoms subside within a day or two. UTIs that spread to the kidneys, however, may cause permanent kidney damage, especially in the elderly and the very young. Conditions or diseases that result in chronic or recurrent UTIs may damage the kidneys and, in some cases, cause kidney failure. Renal failure and septicaemia can be lifethreatening conditions. They require immediate treatment, which often involves hospitalization. In pregnant women, a UTI can lead to premature labour and delivery and cause high blood pressure. In men, a UTI can cause prostate infection and inflammation, which can be difficult to treat [14]. Further categorization of the infection by clinical syndrome and by host (i.e., acute cystitis in young women, acute pyelonephritis, catheter-related infection, infection in men, asymptomatic bacteriuria in the elderly) help the physician determine the most appropriate diagnostic and management strategies [55].

\section{Urinary tract infection and renal diseases complications}

Urologists rarely need to consider bacteria beyond their role in infectious disease. However, emerging evidence shows that the microorganisms inhabiting many sites of the body, including the urinary tract, which has long been assumed sterile in healthy individuals, might have a role in maintaining urinary health. Studies of the urinary microbiota have identified remarkable differences between healthy populations and those with urologic diseases. Microorganisms at sites distal to the kidney, bladder and urethra are likely to have a profound effect on urologic health, both positive and negative, owing to their metabolic output and other contributions [56]. Urinary tract infections (UTIs) belong to the most common infectious diseases worldwide [57]. It is one of the infections that could lead to chronic kidney disease; most of the offending isolates are usually Gramnegative bacteria such as Escherichia coli, and adolescent age groups are a special group of individuals who indulge in some risk behavior that could predispose them to urinary tract infections with possible mixed flora [58]. In febrile newborns, particularly those born prematurely and with a low birth weight, UTI is the most common bacterial infection, and vesicoureteral reflux (VUR) predisposes to UTI and renal scarring [40]. Newborns with UTI have a high incidence of congenital anomalies of kidney and urinary tract anomalies, and hence should undergo renal imaging. A study of paediatric end-stage renal disease (ESRD) in a tertiary hospital in South West Nigeria revealed that the incidence of paediatric ESRD in Ibadan is higher than previous reports from sub-Saharan Africa. Glomerulonephritis and then congenital anomalies of the kidneys and urinary tract (CAKUT) are the most common causes [1]. According to them, children and adolescents with end-stage renal disease (ESRD) in sub-Saharan Africa may have the worst outcomes globally, while barriers to management include late presentation, poor socioeconomic conditions, and absence of medical insurance, limited diagnostic facilities and non-availability of chronic renal replacement therapy (RRT). Also, their report indicated that mortality is high, primarily due to lack of resources, and highlighted that Preventive nephrology and chronic renal replacement therapy (RRT) programmes are urgently needed.

Referring to UTI and its complications, Tuerlinckx et al. [59] stated that UTI leads to Pyelonephritis, which in turn may lead to severe renal damage (renal scarring), with possible arterial hypertension and renal insufficiency, noting that treatment and prognosis are closely related to a number of risk factors such as clinical, biological, radiological and scintigraphic data. According to Shakya et al. [18], UTI is the commonest bacterial infection occurring in renal disorder patients and is associated with significant morbidity, while Khan and Ahmed [30] also reported infection, especially of urinary tract, as being the leading cause of acute renal failure (ARF) in Diabetics, with outcome reportedly being favorable in those who don't require dialysis. Significant epidemiologic associations with chronic kidney disease and ESRD have been noted for Nephrolithiasis, a highly prevalent disorder affecting approximately one in eleven people, and are associated with multiple complications including hypertension, cardiovascular disease, and chronic kidney disease. Corroborating evidence supporting the presence of kidney disease in stone formers includes the variability of renal function by stone type, the positive association of stone size with renal dysfunction, the presence of markers of renal injury in the urine of even asymptomatic stone formers, and direct evidence of renal tissue injury on histopathology. Proposed pathogenic mechanisms include recurrent obstruction and comorbid conditions such as recurrent urinary tract infections and structural abnormalities [45]. Thus, urinary tract infection often gives rise to Kidney diseases as part of the complications. Hence, they are of paramount importance in early diagnosis and management of renal diseases. Usually, urinary tract infections are harmless and can be cured easily. It is an infection that affects part of the urinary tract and it has no direct relationship with kidney. However, repeated UTI often turn into pyelonephritis (inflammation of the kidney). This worsens renal tissues seriously and causes kidney damages. Chronic kidney disease causes no obvious symptoms in early stage, so it is important to be discovered quite timely, but if not timely diagnosed or properly handled, will lead to kidney failure directly [16]. In some cases, a UTI may lead to an infection in the bloodstream (septicaemia) that can be life-threatening. Understandably, due to the often asymptomatic and mild nature of UTIs, the danger they pose as prelude to some renal disease conditions are often underestimated and overlooked. Chronic renal failure for instance, like asymptomatic UTI, produces no symptom until the disease has progressed to an advanced stage. Kidney failure is a serious illness condition in which kidneys are unable in maintaining patient's life. With end stage kidney failure, dialysis or kidney transplant will be 
needed to remove toxins in patient's blood which is normally done by our kidneys. Otherwise, the toxins circulate with blood and threaten any part of patient's organs. Chronic kidney failure cannot be cured, but with effective and timely treatment, the progression of kidney disease can be stopped and end stage kidney failure can be avoided effectively [16]. The Pathogenesis of renal disease from both symptomatic and asymptomatic UTI may be through haematogenous, lymphatic, or more commonly, the ascending routes, from the urethra. The causative bacteria agents like $E$. coli usually get to the kidney by retrograde movement from the urethra to the bladder and finally the kidney or by haematological spread where the renal tissues are the first part of the tract to be infected, thereby initiating renal damage [60].

In normal kidneys with no underlying structural or functional abnormalities, microbial virulence factors are crucial to disease development. Each organism possess a set of virulence factors which helps it in ascending urinary tract, establish itself against the host's resisting factors (i.e. defense mechanisms), and then establishing an infection [33,57,61-64]. For uropathogenic E. coli (UPEC) for instance, its ability to enter the urinary tract and cause an infection has become its special identification characteristic that marks it out among the commensal faecal flora. Many of potential virulence or fitness factors occur moreover with high redundancy [57]. For instance, to establish infection in the urinary tract, E. coli has to overcome several defense strategies of the host, including the urine flow, exfoliation of urothelial cells, endogenous antimicrobial factors and invading neutrophils. Thus, UPEC harbour a number of virulence and fitness factors enabling the bacterium to resist and overcome these different defense mechanisms [57]. Fimbriae are inevitable for adherence to and invasion into the host cells; the pilus is an established virulence factor in UPEC and indispensable for successful infection of the urinary tract. Flagella and toxins promote bacterial dissemination, while different iron-acquisition systems allow bacterial survival in the ironlimited environment of the urinary tract. While the host immune response to UPEC is primarily mediated by toll-like receptors recognizing lipopolysaccharide, flagella and other structures on the bacterial surface, UPEC have the capacity to subvert this immune response of the host by means of actively impacting on proinflammatory signaling pathways, or by physical masking of immunogenic structures. The large repertoire of bacterial virulence and fitness factors in combination with host-related differences results in a complex interaction between host and pathogen in the urinary tract [57].

Apart from UPEC, between $70 \%$ and $95 \%$ of urinary tract infections (UTI) are said to be caused by strains of Escherichia coli often termed Extraintestinal Pathogenic E. coli (ExPEC) [65]. These possess specific virulence traits allowing them to colonize more inhospitable environments, such as the urogenital tract. Some ExPEC isolates from humans have similar virulence factor profiles to ExPEC isolates from animals, and because of the potential for these strains to cause UTI in people, these infections have been referred to as foodborne UTI (FUTI). Finding similarities in ExPEC in animals and humans is not necessarily proof of transmission, particularly a unidirectional pathway from animals to humans; similarities in virulence factor profiles should be expected given the specific bacterial requirements for colonizing physiological compartments with similar characteristics in all animals. Many of the most important strains of human ExPEC globally, such as ST131, are highly virulent and clonal, implying routes of transmission other than food. Documenting routes of transmission is particularly difficult due to the wide range of potential ExPEC sources, including the human intestinal tract, and non-human reservoirs such as food animals and retail meat products, sewage and other environmental sources, and companion animals. The significant environmental reservoir of ExPEC, including strains such as ST131, could potentially explain much more completely the global dissemination of virulent ExPEC clones and the rapid dissemination of new strains within the community. Taken in its totality, the link between ExPEC in animals and UTI in humans might exist, but studies conducted to date do not enable an estimation of the relative importance of this route of transmission. To reduce the burden of illness associated with ExPEC, the scientific community needs to push forward with ecologically-based, scientifically-sound study designs that can address the plethora of ways in which E. coli can spread [65]. In the case of Proteus spp for instance, virulence factors and properties mediating infectious process are swarming phenomenon, adherence due to fimbriae or glycocalyx, flagella, invasiveness, urease, amino acids deaminases, proteases, haemolysins, capsular polysaccharide(CPS), and lipopolysaccharides(LPS, endotoxin). For Pseudomonas aeruginosa, Pseudomonas quinolone signaling system, a component of quorum sensing cascade, is a crucial player in the acute urinary tract infection caused by Pseudomonas aeruginosa [66]. For UPEC, Proteus, Klebsiella and most other pathogenic organisms, type1 fimbriae (as well as type 3 and/or type p, for some) have been emphasized as a very important virulence factor [35,57]. Other identified factors of importance (particularly for UPEC) include OxyR (oxidative stress response regulator) [67] and OmpT (one of the members of the outer membrane protein family) [68].

In contradiction, in renal system with profound alterations in structural and functional integrity of the urethral tract, virulence factors are inconsequential and almost any bacterial species can induce disease [38], consequently, severe complications such as acute or chronic pyelonephritis and/or formation of bladder and kidney stones may develop as a result of even an opportunistic infection of the urinary system by Proteus pathogens [64]. Recurrent UTI by sundry organisms may bring about permanent renal scar, and this leads to chronic renal failure and high blood pressure [14-16,68-70]. Apparently referring to the seriousness of renal scaring as an event culminating in renal damage, Bunting-Early and Figueroa [71] stated that validation and implications of risk model for renal scarring is still needed for primary care practice, while an attempt at a reply regarding this has been made by Shaikh et al., [72]. Hence, UTI can be dangerous if treated late or incompletely because of late diagnosis. Equally so, resultant chronic kidney failure cannot be cured, but with effective and timely treatment, the progression of kidney disease can be stopped and end stage renal failure can be avoided effectively. Since frequently UTI can cause kidney disease directly, it is necessary for us to prevent it in advance. Clinical experiments have shown that drinking large amounts of water will help to remove bacterium out of the urinary tract, which will lower the risk of developing UTI and the consequent kidney failure. Therefore, drinking much more water is very beneficial in our daily life.

\section{Urinary tract infections: diagnosis and treatment}

Diagnosis of UTIs is made with regard to typical complaints/ symptoms, and the presence of leucocytes and nitrites in the urine. A culture is unnecessary in most cases; however, Uncomplicated UTI should be distinguished from complicated UTI which has a risk of severe illness [55]. To find out whether a person has a UTI, the health care provider will ask about urinary symptoms and then test a sample of urine for the presence of bacteria and white blood cells, which are produced by the body to fight infection. Because bacteria can be found 
even in the urine of healthy individuals, a UTI is diagnosed based both on symptoms and a laboratory test. A "clean catch" "midstream" sample of urine in a sterile container is required for laboratory testing. This method of urine collection helps prevent bacteria around the genital area from getting into the sample and confusing the test results. For people with recurring infections and patients in the hospital, the urine may be cultured, using appropriate culture medium. Isolation and identification of offending or bacterial organism (s) or culprits, with their antibiotics sensitivity profile are usually completed 1-3 days. The antibiotics sensitivity result helps to see which medication is best for treating the infection [14-16]. Additional tests may be ordered (in case of recurrent UTIs) to determine if the person's urinary tract is normal. They include kidney and bladder ultrasound, voiding cystourethrogram, computerized tomography (CT) scans, magnetic resonance imaging (MRI), radionuclides scan, urodynamics, and cystoscopy $[4,15]$ Varieties of these tests have been adopted in several case evaluations of UTIs cum renal pathology scenarios both locally $[43,73]$ and elsewhere[39,41,74,75], and limitations to using some of them also noted (and most times, these had a lot to do with age and specific conditions of individual patients), thus generating debates as to the applicability of some of the tests.

Surveys have shown that incidences of the various microbial aetiological agents of UTI are reasonably consistent. Many different microorganisms can cause UTIs though the most common pathogens causing the simple ones in the community are Escherichia coli and other Enterobacteriacae, which accounts for approximately $75 \%$ of the isolates [9,17-19,29,58,76-80]. Escherichia coli (E. coli) remains the predominant uropathogens $(80 \%)$ isolated in acute community acquired uncomplicated infections, followed by staphylococcus saprophyticus (10-15) [9,17-19,29,58,77-85]. Klebsiella, Enterobacter, Proteus and Enterococci infrequently cause uncomplicated cystitis and pyelonephritis [17-19,27,58,80,86]. Enterococci, though commensals in adult feces are important nosocomial pathogens. The most common nosocomial infection caused by these organisms is urinary tract infection [80].

However, the pathogens traditionally associated with UTI are changing many of their features, particularly because of antimicrobial resistance $[20,83]$. The aetiology of UTI is also affected by underlying host factors that complicate UTI such as age, diabetes, spinal cord injury or catheterization, presence of anatomic, metabolic or immunologic underlying disease [27]. Thus, depending on the interplay of these host factors, UTI may become complicated or remain uncomplicated. Consequently, complicated UTI has a more diverse aetiology than uncomplicated UTI, and organisms that rarely cause disease in healthy patients can cause significant disease in hosts with anatomic, metabolic or immunologic underlying disease. The majority of community acquired symptomatic UTIs in the elderly women are caused by E. coli $[27,83,84]$. In a study at Ile-Ife, Nigeria, using hospital data, Ako-Nai et al. [85] showed that $86 \%$ of all cases of UTI were 21 years and above of which $81.3 \%$ in that age group were females, while only $20.7 \%$ of the case were males. Eleven organisms were isolated with E. coli, Klebsiella spp, and Staphylococcus aureus respectively representing $36.1 \%, 22.8 \%$ and $15.4 \%$ of the total bacterial isolates. Another study among the patients of a Nigerian teaching hospital revealed that Proteus species accounted for 33\% of the total organisms causing UTI during a one-year study period, and this occurred more from the age of 55 years upwards in males, while in females they were more evenly distributed. Infections by gram-positive organisms are also common, and polymicrobial infections account for up to 1 in 3 infections in the elderly. In comparison, the most common organisms isolated in children with uncomplicated UTI are enterobacteriaceae [86].

A study of the changing pattern of bacteriuria among asymptomatic secondary school adolescents within Enugu, South East Nigeria [58], showed a prevalence rate of $9.7 \%(61 / 628)$. While Gram-positive bacteria were isolated in $77.1 \%$ (47/61) of samples, Gram-negative bacteria were isolated in $22.9 \%$ (14/61) of samples. Staphylococcus saprophyticus was the most common gram-positive organism isolated consisting of $38.3 \%$ (18/47), while E. coli was the most common gramnegative bacteria isolated comprising $64.2 \%$ (9/14). Other grampositive bacteria isolated were Staphylococcus auerus, and Staphylococcus epididymis, while all isolated bacteria were more common in females 44/61 (72.1\%) than males $17 / 61$ (27.9\%). In another study that investigated Pattern of asymptomatic bacteriuria among pregnant women attending an antenatal clinic at a private health facility in Benin, South-South Nigeria [78], the prevalence of ASB was $13.8 \%$ by urine culture and $43.8 \%$ by urine microscopy among antenatal attendees in Faith Medical Centre, Benin City. There was no relationship between ASB and socio-economic factor ( $\mathrm{P}$ value $=0.1267)$. There was also no significant specific trend between ASB and age ( $P$ value $=0.0578$ ). Using urine culture as gold standard, the sensitivity of urine microscopy was $90.9 \%$, the specificity was $49.3 \%$, the positive predictive value was $22.2 \%$ and the negative predictive value was $97.1 \%$. As part of their conclusion, "the current practice of diagnosing and treating ASB based on urine microscopy needs to be reviewed since the specificity of urine microscopy is very low. Also the practice of screening pregnant women only at the time of booking can lead to under-diagnosis of ASB. This is so because most women who develop this condition later in the course of antenatal care will be missed" [78]. However, the study of Akerele et al. [25,28] among pregnant women revealed a prevalence of $86.6 \%$ significant bacteriuria. Of this $7.1 \%$ were of mixed bacterial colonies, while $91 \%$ were of single bacterial colonies. Staphylococcus aureus (29.8\%), E. coli (29.1) and Klebsiella pneumoniae (21.5\%) were the most frequently isolated organisms, thus revealing a seemingly different pattern of distribution, perhaps due to pregnancy state. Aetiologic pathogens associated with UTI among patients with diabetes include Klebsiella spp., Group B streptococci, and Enterococcus spp., as well as E. coli. Patients with spinal cord injuries commonly have $E$. coli infections. Other common uropathogens include Pseudomonas spp and Proteus mirabilis. Gramnegative bacteria of the genus Proteus from the family Enterobacteriaceae are opportunistic pathogens which cause mainly wounds and urinary tract infections (UTI), the latter leading to sever complications such as acute or chronic pyelonephritis and formation of bladder and kidney stones [64]. In a study of prevalence of significant bacteriuria among symptomatic and asymptomatic homozygous sickle cell disease patients in a tertiary hospital in Lagos, Nigeria, Akinbami et al., [29] found that only $9 \%(9 / 100)$ had significant bacteriuria, while $44.4 \%$ (4/9) participants who had significant bacteriuria were asymptomatic. Escherichia coli was isolated in $66.6 \%(6 / 9)$ participants who had significant bacteriuria while Klebsiella oxytoca, Klebsiella pneumonia and Staphylococcus aureus (11.11\%) was isolated in each of the remaining three participants. Thus, significant bacteriuria was found in only one-tenth of sickle cell patients, even as nearly half of the participants who had significant growth had asymptomatic bacteriuria. Studying the Spectrum of bacterial pathogens and their antibiogram from cases of urinary tract infection among renal disorder patients, urine samples were collected from 300 clinically-suspected cases of UTI among renal disorder patients and investigated by conventional semi-quantitative culture technique, microscopy and antibiotic 
susceptibility test. Significant bacteriuria was detected in $34 \%$ of the total subjects, mostly from patients with Chronic Kidney Disease. Incidence of bacteriuria was found higher in females (40.40\%) than in males $(27.52 \%)$ and mostly occurred in elderly patients. Escherichia coli $(62.75 \%)$ was the predominant isolate followed by Klebsiella pneumoniae (10.78\%), Staphylococcus aureus (9.80\%), Coagulase negative Staphylococcus aureus (CoNS) (5.88\%), Enterococcus spp (3.92\%), Klebsiella oxytoca (2.00\%), Pseudomonas aeruginosa $(2.00 \%)$, Proteus mirabilis $(2.00 \%)$ and Proteus vulgaris (1.00\%). Multidrug resistance was observed in $68.82 \%$ of the total bacterial isolates [18]. In an earlier similar study in India, [9] observed that out of 280 urine samples 168 (60\%) patients tested positive for culture. Escherishia coli was still the most common isolate (44.96\%) followed by Enterobacter spp (17.83\%) and Klebsiella spp (14.72\%) amongst the gram negative bacilli. Amongst the gram positive bacteria Staphylococcus aureus $(92.3 \%)$ was commonest. In terms of antimicrobial sensitivity, E. coli which was the main isolate identified was found to be highly susceptible to Amikacin (82.2\%) followed by Ciprofloxacin (78.2\%), Gentamicin (80.4\%), Ampicillin (59\%) and Nitrofurantoin (57\%). This study finding thus showed that $E$. coli isolates were the predominant pathogens and showed increasing resistance pattern to the commonly prescribed drugs in private practice that in turn leaves the clinicians with very few alternative options of drugs for the treatment of UTIs.

Beside bacterial organisms, fungal species are often isolated as part of causal organisms of UTI as revealed in the study of Osawa et al., [19]. The most frequently isolated Candida was Candida albicans, which showed good (100\%) susceptibilities to 5-fluorocytosine (5-FC) and fluconazole (FLCZ) but not to voriconazole (VRCZ), followed by C. glabrata. Intensive Care Unit (ICU) was the greatest source of candida-positive samples, and the most relevant underlying diseases of ICU patients were pneumonia followed by renal failure and post liver transplantation status. Combined isolation with other bacteria was seen in 27 cases (42.9\%) in 2009, 25 (33.3\%) in 2010 and 31 (31.3\%) in 2011 and comparatively often seen in non-ICU patients. Other candidas than $C$. albicans showed significantly decreased susceptibility to FLCZ over these 3 years $(\mathrm{P}=0.004)$. Apart from these organisms of UTI commonly found in renal diseases, a case of UTI has been reported in a 60-year-old chronic kidney disease patient due to Paenibacilli, a rare Gram positive, aerobic spore bearing bacilli normally found in the environment, and not known to cause human disease until recently; few species of this genus have been reported to cause infections in humans [87]. Similarly, apart from known pathogenesis and diagnostic approaches, a recent predictive model of chronic kidney disease (CKD) by Quirino et al. [88] revealed congenital anomalies of the kidney and urinary tract (CAKUT) of patients as predictive events that could lead to complications of UTI to renal pathology. This predictive model of CKD may therefore contribute to an early identification of a subgroup of patients at high risk for renal impairment.

Talking about treatment, UTIs are among the most common infectious diseases and contribute to high financial burden worldwide, particularly in the face of daunting multidrug resistance (MDR) of most causal organisms. Administration of appropriate antibiotic therapy is therefore the key to achieving good therapeutic outcomes [20]. Most UTIs are caused by bacteria, which are treated with bacteria-fighting medications called antibiotics or antimicrobials. The choice of medication and length of treatment depend on the patient's history and the type of bacteria causing the infection. Some antibiotics may be ruled out if a person has allergies to them. The sensitivity test takes 48 hours to complete and is especially useful in helping the health care provider select the antibiotic most likely to be effective in treating an infection. Longer treatment may be needed if the first antibiotic given is not effective. For purposes of sound treatment, it is important that, diagnostically, uncomplicated UTI should be distinguished from complicated UTI, which has a risk of severe illness. Complicated UTIs occur when a person- for example, a pregnant woman or a transplant patient- is weakened by another condition. A UTI is also complicated when a person has structural or functional abnormality of the urinary tract such as an obstructive kidney stone or prostate enlargement that squeezes the urethra. Health care providers should assume that men and boys have a complicated UTI until proven otherwise [15]. Severely ill patients with kidney infections may be hospitalized until they can take fluids and needed medications on their own. Kidney infections may require several weeks of antibiotic treatment. Uncomplicated UTIs are caused by a predictable group of susceptible organisms. These infections can be empirically treated without the need for urine cultures, while complicated infections are diagnosed by quantitative urine cultures, and require a more prolonged course of therapy. Asymptomatic bacteriuria rarely requires treatment and is not associated with increased morbidity in the elderly patients. A shortterm therapy with trimethoprim-sulfamthoxazole (TMP-SMX) or TMP alone or nitrofurantoin is successful in over $80 \%$ of cases $[23,25,55]$. Despite these, a great deal of new generation antibiotics is also available for treatments of varieties of UTI. However, a major setback being faced in the treatment of cases of UTIs is the increasing resistance being developed by many UTI-causal organisms against many antimicrobial drugs $[20,82]$. Drug resistance is often associated with biofilm formation, which is becoming a predominant feature in nosocomial infections. Since biofilms are increasingly resistant to antibiotics, making monotherapy ineffective, combination therapy appears to be relevant for their eradication. This approach is confirmed by the result of a study that assessed the potential of azithromycin (AZM) and ciprofloxacin (CIP) alone and in combination in vitro and in a mouse model of UTI induced with biofilm cells of Pseudomonas aeruginosa [89]. Based on positive outcomes, the study concluded that AZM+CIP therapy holds promise against biofilm-associated UTIs as it confers antibacterial, immunomodulatory and anti-inflammatory effects.

Still, towards successful therapy for UTIs, Chen et al. [20] reviewed the current status of global or regional epidemiology, especially on the antimicrobial resistance and several potential agents against complicated UTIs by multidrug-resistant (MDR) pathogens, and summarized the susceptibility status on several major surveillance programs on uropathogens, focusing on Enterobacteriaceae, Pseudomonas aeruginosa, Acinetobacter baumannii, methicillinresistant Staphylococcus aureus, and vancomycin-resistant enterococci, as well as the current perspectives of several potential antimicrobials against MDR uropathogens available for UTIs. Their expert opinion is that High resistance to broad-spectrum antibiotics, especially to extended-spectrum (sup)-lactams, carbapenems, and fluoroquinolones among uropathogens emerges as a critical problem in many countries. According to them, appropriate antimicrobial stewardship and continuous surveillance are necessary to monitor the trends of susceptibility for main pathogens. For these MDR uropathogens, polymyxin, fosfomycin, tigecycline, nitrofurantoin, linezolid, and daptomycin might be potential treatments for patients with uncomplicated and complicated UTIs in some countries, if regulation of such countries approve of their use. However, more clinical evidence and more extensive meta-analyses are needed to evaluate and confirm the effectiveness of their usage in countries with 
a high prevalence of multidrug resistance. Still, contending with the problem of drug resistance, Ferreiro et al. [74] noted that treatment of complicated urinary tract infection particularly in children has still remained a matter of debate, warranting that, in some hospitals, antimicrobial treatment is initiated intravenously, and the duration of this treatment is adapted according to the results of a Tc- $99 \mathrm{~m}$ dimercaptosuccinic acid (DMSA) scintigraphy.

\section{UTIs and renal diseases: A rising trend in Nigeria}

As stated earlier, evidence shows there has been a considerable rise in the incidence of renal diseases in Nigeria in the last three decades. Result of a survey by this author (unpublished) showed there was a $265 \%$ rise between 1984 and 1993 based on records from the University of Nigeria Teaching Hospital, Enugu, Nigeria, and that trend has remained consistently so ever since then as confirmed by other studies since then [1-4]. Though factors responsible for this rising trend has not been clearly documented, known risk factors for renal diseases such as hypertension, diabetes mellitus, drugs, food poisoning and other environmentally-related toxicities, as well as urinary tract infections affect significant proportion of our population. The contribution of UTI to the renal disease burden of our land is not yet very clearly documented, and this underscores the present study aimed at establishing the incidence and identity of the causal organisms of UTI in renal disease of our environment, using the renal disease patients of the University of Nigeria Teaching Hospital, Enugu, Nigeria as a case study. The latter is among the first generation teaching hospitals in Nigeria with a good blend of various expertise, including a functional renal Centre. With its vintage location at the center of the south eastern Nigeria, it remains a major referral tertiary hospital for parts of Nigeria, especially the south eastern states. It is hoped that the findings of this study would throw more light on the incidence of UTI, the identity and contributions of the causal organisms in the renal disease burden of Nigeria.

\section{Materials and Method}

\section{Subjects}

The subjects of this study consisted of one hundred patients (43 males and 57 females, and aged between 17 and 65 years) attending the renal clinic of the University of Nigeria Teaching Hospital, Enugu for various forms of kidney diseases.

Ethical clearance: Ethical clearance was obtained from the Institutional Review Committee of the Department of Medicine, University of Nigeria Teaching Hospital, Enugu, Nigeria. The nature and purpose of the study was explained to the management of the Medicine department and their renal disease patients, following which approval for study was given by the management, and consent for voluntary participation was obtained from the patients.

\section{Procedure}

Midstream urine samples (MSU) were collected into clean sterile screw-capped containers with boric acid (Steriline Ltd, Feltham, England). Standard procedure for the isolation of medical bacteria were employed using cysteine lactose electrolyte deficient medium (CLED) for primary isolation, while identification of the isolates was aided by Grams reaction, sugar fermentation and other biochemical tests including Kligler's iron agar (KIA), catalase, urease, citrate, and vorges-proskern tests [89-91]. Routine urinalysis with Bioscan multistix and microscopic examination of the urine sediments were also carried out. Samples with bacterial counts $>10^{5}$ (by the standard wire loop technique) were recorded as having significant bacteriuria; similarly, samples with more than 3 pus cells per high powered microscope field $(\mathrm{x} 40)$ were reported as having significant pyuria.

\section{Results}

Results show that, on the basis of significant bacteriuria (i.e. $>10^{5}$ colonies/ml), twenty-eight samples had significant bacteriuria (i.e. $28 \%$ bacteriuria), while 12 samples (i.e. 12\%) showed presence of fungal yeast cells, Candida albicans. The results revealed that while the various bacterial species jointly accounted for $70 \%$ of the entire microbial agents responsible for the urinary tract infections among the study subjects, fungal yeast cells Candida albicans, made reckonable contribution of the remaining $30 \%$ (Figure 1).

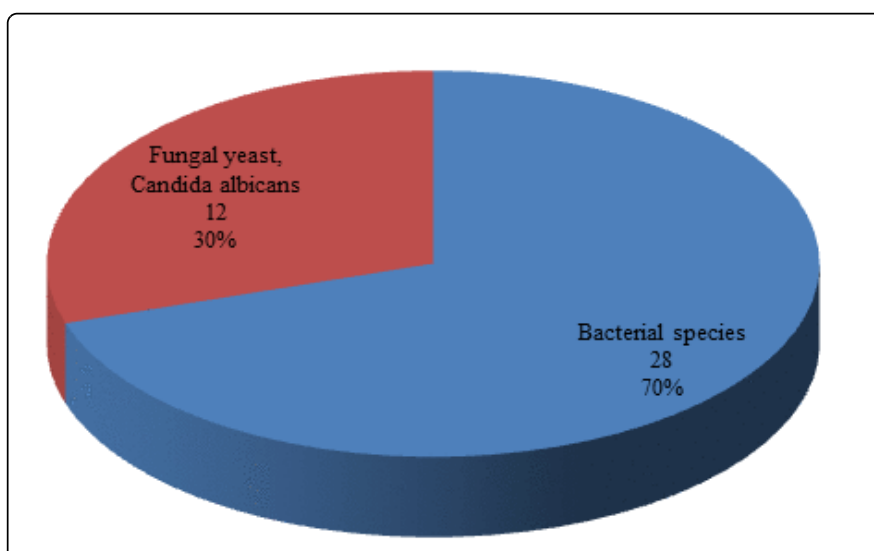

Figure 1: Identity and contributions of microbial groups to UTI among the renal disease patients.

Subsequent microscopic and biochemical characterization of the bacterial isolates revealed the presence of seven species viz Escherichia coli (29\%), Klebsiella spp (22\%), Proteus mirabilis (14\%), Pseudomonas aeruginosa (7\%), Streptococcus faecalis (7\%), Staphylococcus aureus (7\%) and Staphylococcus epidermidis (14\%) as the dominant bacterial organisms responsible for urinary tract infections among these (Figure 2).

Sex distribution of the isolated organisms are shown in Figure 3, and revealed that while Staphylococcus aureus (33\%) was isolated only from the males, E. Coli, Proteus mirabilis, Streptococcus faecalis and Pseudomonas aeruginosa were isolated only from the females; Klebsiella spp was isolated from the males (33\%) and females (67\%) respectively, while Staph epidermidis was isolated equally (50\%) from both sexes.

Table 1 shows the result of urinalysis, revealing the additional presence of proteinuria (84\%), glycosuria (6\%), haematuria (45\%) and pyuria (79\%) among others, suggesting renal disease conditions with possible complications by diabetes mellitus or vice versa, while in table 2 , the results of the microscopic examination of samples are shown. 


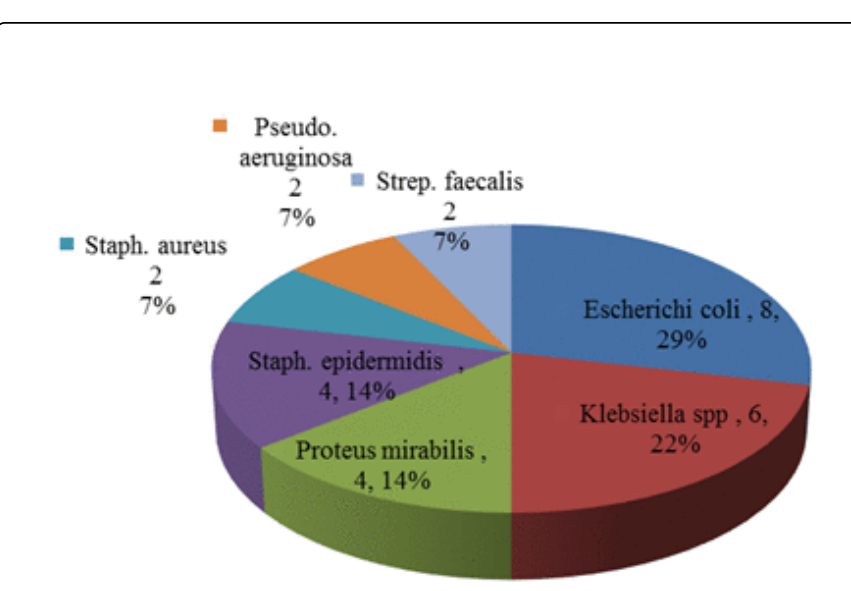

Figure 2: Incidence and identity of isolated bacterial organisms responsible for uti among renal disease patients.

\section{Discussion}

The study showed that the overall incidence of bacteriuria among renal patients in the University of Nigeria Teaching Hospital Enugu is 28\%. Microscopic examination of urine samples (Table2) revealed that pyuria occurred in a much higher percentage of the patients $(73 \%)$, majority of whom remained abacteriuric. Many possible explanations can be given for this. Antibiotic administration prior to bacterial cultures could lead to suppression of bacterial growth [90-92], and some exacting organisms may not grow on the specified media but could readily give rise to urinary tract infections and pyuria [90-93]. The implication of this is that a much higher percentage of these patients could actually be having UTI than are actually revealed by bacterial culture alone which yielded only $28 \%$ positive bacteria isolates/recovery (accountable for $70 \%$ of the microorganisms responsible for UTI among these patients (Figure1). This trend could be likened to the findings of Alfred et al., [78] in which lower prevalence (13.8\%) of ASB was obtained by urine culture compared to a higher prevalence $(43.8 \%)$ obtained by urine microscopy among antenatal attendees in a Medical facility in Benin City, Nigeria.

\section{-Males $\square$ Females}

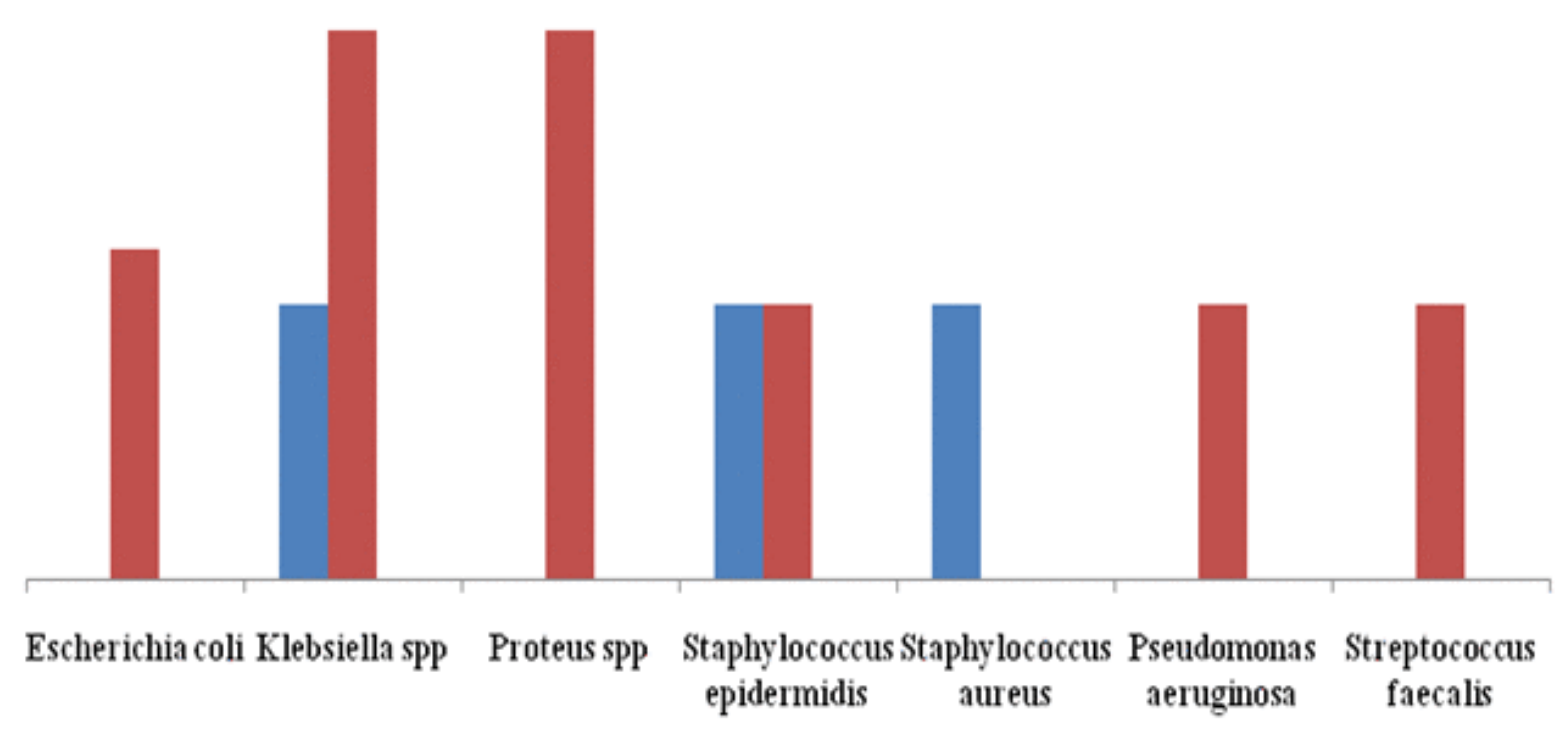

Figure 3: Sex distribution of the identified bacterial organisms.

\begin{tabular}{|c|c|c|}
\hline Parameter & Occurrence & Percentage of Occurrence (\%) \\
\hline Sugar & 6 & 6 \\
\hline Protein & 83 & 83 \\
\hline Leucocytes & 79 & 79 \\
\hline Red blood cells & 45 & 45 \\
\hline Yeast cells & 12 & 12 \\
\hline
\end{tabular}

Distribution of the bacterial isolates according to gender (Figure 2) revealed that women had a higher infection rate than men. This agrees with known pattern, as previous works has consistently reported higher incidence of UTI among women [18,54,58,85]. Several reasons have been adduced for this: short length of female urethra [14-16,94], sexual intercourse [95] (maybe because a woman is receiving during intercourse); massaging of the urethra as a result of instrumentation, and this can force bacteria into the urinary bladder thereby initiating infection [14-16,26,32-36,95-98]. However, unlike this seemingly usual pattern, more UTI cases were reported in males than females in the study of Otajevwo [79], in which Occurrence of UTI in male and

Table 1: Biochemical and microscopic findings in the urine samples of the renal patients. 


\begin{tabular}{|c|c|}
\hline Parameter & Occurrence and Percentage of Occurrence \\
\hline Significant bacteriuria with Significant pyuria & $21(21 \%)$ \\
\hline Significant bacteriuria without significant pyuria & $7(7 \%)$ \\
\hline Significant pyuria without significant bacteriuria & $52(52 \%)$ \\
\hline No significant pyuria and no significant bacteriuria & $20(20 \%)$ \\
\hline
\end{tabular}

Table 2: Distribution of bacteriuria and pyuria among the renal patients.

On the incidence and identity of the various aetiological agents (Figure3) it was observed that, in this study, E. coli (29\%), Klebsiella spp (22\%), Proteus spp (14\%), and S. aureus (14\%) were the most frequently isolated causal agents of UTI. In agreement with this findings, plethora of previous works have also reported these same organisms as leading cause of UTI in diverse settings or environments $[9,17-19,27-29,55,58,64,76-80,84,86,99]$. It is also noteworthy that, in this study, enteric organisms especially Escherichia coli (29\%) caused the majority of the infections in females as was also the case in reports of some previous works [9,14-19,29,58,77,78,80,83]. Several reports have shown that organisms causing UTI are the same strains that colonize the vaginal introituses, and are found in the stools of the patients $[9,17,19,77,80,100,101]$. According to Nwokocha et al, [58], urinary tract infection is one of the infections that could lead to chronic kidney disease, and most of the offending isolates are usually Gram-negative bacteria such as Escherichia coli. Rozalski [64] has also stated that Gram-negative bacteria of the genus Proteus from the Enterobacteriaceae family are opportunistic pathogens which cause mainly wounds and urinary tract infections (UTI), the latter leading to severe complications, such as acute or chronic pyelonephritis and formation of bladder and kidney stones. Incidentally, majority of these isolates are Gram-negative organisms and members of the Enterobacteriaceae family proven to be culprits in majority of cases of UTIs, the later eventually producing various forms of renal diseases as complications. The pattern observed in this study regarding the organisms and their possible complicity in renal diseases is in conformity with a trend reported previously by others $[1,18,30,40,45,56,57,59]$. These reports compel the conclusion that infections in these patients are primarily by the ascending route.

Virulence factors and properties mediating infectious process, and in this case, promoting the development of UTI include bacterial adherence to uroepithelial surfaces $[57,63]$ and this is enhanced by the possession of type1, type 3 and type $\mathrm{p}$ fimbriae, as the case may be $[33,35,57,102]$, production of haemolysin as in E. coli $[35,57,61,65]$ and resistance to serum bactericidal activity $[62,67]$. In the case of Proteus spp for instance, such factors include swarming phenomenon, adherence due to fimbriae or glycocalyx, possession of flagella, invasiveness, urease, amino acids deaminases, proteases, haemolysins, capsular polysaccharide (CPS), and lipopolysaccharides (LPS, endotoxin) [35,57,64,67], while for Pseudomonas aeruginosa, Pseudomonas quinolone signaling system, a component of quorum sensing cascade, is a crucial player in the acute urinary tract infection caused by Pseudomonas aeruginosa [66]. In contradiction, in renal system with profound alterations in structural and functional integrity of the urethral tract (most likely among our study subjects, being renal disease patients), virulence factors are almost inconsequential since most aspects of the host defense mechanisms are compromised and almost any bacterial species that ordinarily would be harmless, could initiate / induce disease, as observed previously by Lomberg et al. [38]. The anti-adherence mechanisms of the renal tract, the mechanical effects of micturition and urine flow, and the host immune mechanisms are some of the patient's defenses that are compromised in renal disease [64]. Host production of antibodies against hemolysin and cytotoxic necrotizing factor type 1 (CNF1) has been demonstrated to reduce bladder inflammation in a mouse model of urinary tract infection with toxigenic uropathogenic Escherichia coli [103] and this, when replicated in humans, could be a boost to host immune response against UTI causal organisms, especially UPEC.

Apart from these, it is noteworthy that vesicouthral reflux predispose to renal scar, thus facilitating renal damage [18,39-42,75]. Consequently, sever complications such as acute or chronic pyelonephritis, formation of bladder and/or kidney stones or sundry other renal disease conditions may have developed among this study subjects as a result of even an opportunistic infection of the urinary system by Proteus pathogens or any other opportunistic organism, as noted previously by Rozalski [64]. This may explain the role/ contributions of Proteus spp (one of the isolates in this study), and/or Staphylococcus epidermidis (another isolate, and a commonly commensal organism that is usually non-pathogenic under normal circumstances), to the UTI statistics obtained in this study, and by extension, the renal disease burden of our environment. That a fungal yeast, Candida albicans (30\%) made reasonable presence as one of the major microbial causal agents of UTI in these subjects (Figure1) suggests that the contributions of UTI to the renal disease burden of our land is a function of not only bacterial organisms but also of a multiple other microbial and/or other aetiological agents replete in our usually unwholesome tropical environment, thus reflecting the role of environmental factors in the burdens of not only renal pathology but also of the various other diseases of our land. This is supported by the findings of Osawa et al., [19] in which Candida albicans, and Candida glabrata, were among the organisms isolated from the renal patients of the Intensive Care Unit (ICU) and non ICU in their three-year study (2009-2011). Candida albicans-a fungal organism had remained one of the major isolates in cases of UTI $[76,78]$.

The findings of this study in terms of distribution of bacteriuria and pyuria (Table 3 ) fit into at least three of the eight possible preliminary diagnoses of UTI defined by Moffet [104] based on three diagnostic criteria: subjective and objective clinical findings, the presence or absence of pyuria, and bacteriuria. Based on the consideration of this criteria, one could have typical UTI defined as having the characteristic clinical findings, pyuria(5-10 leucocytes per high powered field of centrifuged urine) and significant bacteriuria $\left(10^{5}\right.$ bacterial colonies $/ \mathrm{ml}$ or above); suspected UTI without pyuria or bacteriuria, commonly occurring due to bacterial urethritis, over hydration with frequent voiding, suppressive antibiotic therapy, adenoviral cystitis, urethral irritation from pinworms or detergent bubble baths; presumptive UTI 
without bacteriuria, rarely secondary to urethral obstruction but usually related to specific or non-specific urethritis; probable UTI with bacteriuria but without pyuria which demand a repeat of urine culture for clarification; asymptomatic bacteriuria and pyuria possibly due to suppressive chemotherapy, contamination, or undue delay in bacterial culture; asymptomatic bacteriuria without pyuria either due to reasons noted immediately above or related to preceding UTI with subsequent disappearance of symptoms and pyuria; asymptomatic pyuria associated with several examples cited above as well as poor urine collection, dilute urine, poor culture techniques, or secondary to renal tuberculosis, nephritis, fever and extreme dehydration; or no bacterial infection with absence of all three variables noted.

Hence, adoption of leucocytes presence in urine (pyuria) as part of diagnostic criteria for UTI revealed that the actual number of UTI cases is likely to be higher than actually established using positive urine culture alone. This is because, the combined contributions made by the sub-populations with significant pyuria component and that with significant bacteriuria component i.e., "significant bacteriuria with significant pyuria (21\%)", "significant pyuria without significant bacteriuria (52\%)" and "significant bacteriuria without significant pyuria (7\%)" when compared with the significant bacteriuric population obtained from positive urine culture alone (28\%), makes the later pale into insignificant position $(>0.05)$. Thus, this significant pyuric group (usually with 5-10 leucocytes per high field), though abacteriuric, may possibly be so because of antimicrobial chemotherapeutically-induced suppression[104,92] (and this is very possible among our study subjects following inclusion of antibiotics as part of their treatment regimen for established renal disease states/ complications), poor urine collection, dilute urine, poor culture techniques, nephritis, fever and extreme dehydration(also possible among our subjects from possible overuse of diuretics indicated for oedema commonly seen among renal disease patients).

Even the sub-population "no significant bacteriuria with no significant pyuria (20\%)" may not be wished away entirely since according to Moffet [104], the reason for this may, in addition to some of the factors above, includes bacterial urethritis, over hydration with frequent voiding, suppressive antibiotic therapy, adenoviral cystitis, and urethral irritation from pinworms (and helminthiasis is part of common diseases of our unwholesome tropical environment) or other reasons. Consequently, it is evident that relying on a urine cultural colony count of equal to/or greater than $10^{5}$ colony forming units $/ \mathrm{ml}$ in establishing diagnosis of UTI, though more accurate than relying on no culture at all, may still miss infection, particularly if random rather than first- morning concentrated urine specimens are cultured, as observed by Sloky and Todd [105] and Alfred et al., [78] and false negatives are bound to occur. These false negatives, according to Dove et al., [106] could be as high as $28 \%$ in adults. In the present study however, every effort was made to eliminate the factors of poor urine collection, contamination and poor culture technique, among other precautions taken to ensure standard practice aimed at aseptic and maximum organisms' recovery or isolation.

Thus, putting these presumed "False Negatives" into consideration, the number of UTI case diagnoses among the study subjects may indeed become something more tangible than it seems, thus making the contributions of UTI to the renal disease burden of our land something very substantial and therefore quite phenomenal. This verdict when considered alongside the results of urinalysis, revealing the additional presence of proteinuria (84\%), haematuria (45\%) and glycosuria (6\%) among others (Table1), suggests renal disease conditions with possible complications by diabetes mellitus or vice versa. Also in line with the findings in this study, haematuria and proteinuria were also reported in the study of Morenikeji et al., [53], as diagnostic indicators of urinary schistosomiasis caused by schistosoma haematobium as co-infection with UTI among children in an endemic rural community. Other Studies also noted schistosomiasis coinfection as increase risk factor for UTI [50-52], suggesting that schistomiasis could be making some yet-to-be confirmed contribution to the renal disease burden of Nigeria. As at the time of this study, some of the areas under the medical jurisdiction of the UNTH, Enugu (this case-study hospital) were known to be part of the schistosomiasis belt/map of Nigeria.

Still on the role of environmental factors, the contributions of drugs of various types and sources are worth being given a taught. Perhaps in search of cure for the often 'stubborn UTIs' (possibly arising due to multiple drug resistance (MDR) syndrome), our people are known to have resorted to taking all kinds of things in the name of alternative (herbal) medicine, sometimes side by side with their doctors' orthodox medical prescriptions. It is also possible that the active ingredients in some of these drugs may contain substances likely to be nephrotoxic, with potentials of creating the initial renal tissue injuries that kick-start the ultimate renal diseases/failures. This position is supported by the findings of Menon et al., [107]. The authors aimed to assess the development of chronic kidney disease (CKD) after high nephrotoxic medication exposure-associated acute kidney injury (NTMx-AKI) in hospitalized children. They found that six months after NTMx-AKI, $70 \%$ of patients had evidence of residual kidney damage (reduced eGFR, hyperfiltration, proteinuria, or hypertension), few underwent a complete evaluation for $\mathrm{CKD}$, with studies showing an association between AKI and CKD. Similarly, Small and Sandefur [108] described a case of a 22-year-old male who developed severe bilateral flank pain, haematuria, and oliguria (symptoms of acute renal failure) after an isolated recreational ingestion of guaifenesin and dextromethorphan. In my view, a keen observation of early signals of such an AKI at this instance, perhaps aided by diagnostic proteinuria and haematuria (these are associated with acute kidney injury and mortality in critically ill patients) [109] and changes in serum creatinine level (also associated with critical illness and detection of persistent renal dysfunction after AKI [110], might be of great proactive value in initiating measures likely to prevent a possible CKD that may ensue(AKI is a risk factor for development or worsening of resultant $\mathrm{CKD})$.

It is possible therefore, that some of the cases of renal diseases of our land may have their roots traced to the drugs taken by these patients as prescriptions for UTI or other ailments as the case may be, and particularly so for many others some of whom may have resorted to traditional herbal medicines (the toxicological profiles of most of which are yet to be verified) as solution for their perceived 'stubborn UTIs'(a stage given birth to, perhaps by late presentation for treatment, or on account of inadequate treatment). For instance, although evidence for their therapeutic efficacy is limited, herbal traditional Chinese medicine (TCM) preparations are increasingly gaining popularity. However, although adverse effects of TCM were rarely reported in recent years, more cases were being published since 2011, thus providing new clinical challenges [111].

The implication of all these is that the renal diseases burden of Nigeria appears be of multifactorial origin. That is, in addition to the contributions made by UTIs, it is possible that diabetes mellitus and/or other diseases or conditions including possibly urinary schistosomiasis 
(accounting for the haematuria, though possibly not exclusively) are part of the complex scenario defined by factors inherent in our environment (acting singly, synergistically or as complications) that shape/determine the burdens and patterns of renal diseases in Nigeria. My view here is supported by the review of Wanigasuriya [6] concerning a new form of chronic kidney disease that has emerged over the past two decades in the north-central dry zone (particularly, north Central Province) of Sri Lanka where a higher disease burden is ravaging a rural and disadvantaged population involved in rice-paddy in the area, and affects farming. According to the author, "available data suggest that chronic kidney disease of uncertain etiology is an environmentally acquired disease, but to date no definitive causal factor has been identified, while Geographic distribution and research findings suggest a multifactorial etiology".

Indeed, it is my strong opinion that biological agents alone cannot account for this observed rising trend in the renal disease profile of Nigeria. Consequently, further search is warranted for those other factors of our environment fuelling the sustained rising trend. Relating to the unknown factors, there is an urgent need for an epidemiological study to verify an association between diabetes mellitus (despite current knowledge), Schistosomiasis, and use of traditional herbal medicines respectively and development of renal diseases in Nigeria. Regarding use of traditional herbal medicines, this is particularly very important, given the rate of patronage currently enjoyed by both our indigenous traditional medicines and avalanche of other traditional Chinese/Asian herbal medicines currently flooding the Nigerian market under the guise of not just alternative health-care remedies, but also a source of instant wealth creation through downline-uplinebulding marketing networking structures purported to offer graded financial fortunes, instant wealth and other socio-economic prosperity to all those involved in the marketing network. Similarly, it is worrisome to note the alarming metals pollutants load of most of our cities' environments as revealed by a recent study of soil samples conducted in Aba- a densely populated and heavily industrialized commercial city within the South-Eastern Nigeria- a geographical area still under the medical jurisdiction of the UNTH, Enugu as at the time of this study. The results indicated that the mean concentrations for most of the metals (particularly heavy metals) were high with respect to the Nigerian Federal Environmental Protection Agency (FEPA) and World Health Organization (WHO) standards [112]. Given the role of some metals and other physico-chemical entities of the environment in the epidemiology of renal pathologies, these findings cannot be simply glossed over.

Consequently, a more robust study with potential to generate a more extensive data base is hereby recommended. In this regard, toxicology profiles of the traditional healthcare herbal remedies need to be properly verified and documented. In like manner, the various environmental media, particularly, air, soil and water supply sources serving the studied area also need to be evaluated not just for biological factors, but also for metals and other Physico-chemical characteristics to determine possible correlation with renal diseases. This study need is re-enforced by the fact that there is a sustained rising trend in the departure from our hitherto relatively harmless traditional ways of life in favour of a more modern pattern in which, starting from our basic agriculture, food and nutrition, modest industrial activities, to other sundry consumerisms, chemical substances have become part of almost every process, products, byproducts and wastes, despite the inevitability of environment-food chain-pathology dynamics. Who knows, apart from the biological agents as revealed in this study, chemical factors may be part of the conspirators in the Nigerian renal diseases burden.

\section{Summary of Research Findings and Suggestions}

The following are among the major highlights/summary of these study findings, which also represent major contributions in this thematic area to the scientific community:

*The study revealed an overall incidence of $28 \%$ bacteriuria among renal disease patients of UNTH, Enugu. ${ }^{\star}$ Various bacterial species jointly accounted for $70 \%$, while Candida albicans also made reckonable contribution $(30 \%)$ of the entire microbial agents responsible for the UTIs among the subjects.

${ }^{\star}$ Characterization of the bacterial isolates revealed that Escherichia coli (29\%), Klebsiella spp (22\%), Proteus mirabilis (14\%), Pseudomonas aeruginosa (7\%), Streptococcus faecalis (7\%), Staphylococcus aureus (7\%) and Staphylococcus epidermidis (14\%) are the dominant bacterial organisms responsible for UTIs among these patients.

${ }^{\star}$ Adoption of leucocytes presence in urine (pyuria) as part of the diagnostic criteria for UTI revealed that the actual number of UTI cases is likely to be higher than actually established using positive urine culture alone.

${ }^{\star}$ Evidence from urinalysis revealing proteinuria (84\%), haematuria (45\%) and glycosuria (6\%) indicated that, apart from UTIs, diabetes mellitus and/or other disease or conditions including possibly urinary schistosomiasis (possibly accounting for the haematuria, perhaps not exclusively), are part of the complex scenario defined by yet-to-be identified factors inherent in our environment (acting singly, synergistically or as complications to UTIs) that determine the burdens and patterns of renal diseases in Nigeria.

\section{Limitations}

Inadequacies regarding funding are part of the major limitations of this study, and this was responsible for a constricted design that could not accommodate a more extensive study whereby other possible confounders such as diabetes mellitus, hypertension, certain drugs particularly traditional herbal medicines and/or other environmental toxicants such as heavy metals, etc could have been investigated also. It is known that each of these conditions have the proverbial "egg and chick relationship" with renal diseases, just as renal diseases themselves equally have such relationship with the UTIs. In either case, one could give rise to the other either as a primary cause or secondary consequence. In the circumstance, interpretation of data regarding the actual contribution of UTIs to the renal disease burden of the land becomes a very difficult task that would have been made easier when holistic environmental data for all possible causes and confounders of renal disease conditions (medical, biological, and chemical) are available for comparisons.

\section{Recommendations}

Government should improve on research funding, and University management should make the available fund accessible, so as to have a generous research grant for a more elaborate investigation of this problem, since in the opinion of this author, biological agents alone cannot account for this observed rising trend in the renal disease profile of our land. Further search is warranted for those other factors of our environment fuelling the sustained rising trend. Consequently, a 
more robust study with potential to generate a more extensive data base is hereby recommended. In this regard, toxicology profiles of the traditional healthcare herbal remedies need to be properly verified and documented. In like manner, the various environmental media, particularly, air, soil and water supply sources serving the studied area also need to be evaluated not just for biological factors, but also for metals and other Physico-chemical characteristics to determine possible correlation with renal diseases.

\section{Funding and policy aspects}

This study was funded exclusively by self from personal/family funds. Governments in developing countries, particularly Nigeria, must realize that knowledge drives society. It is knowledge that will take the nation/society to its desired developmental heights, and research is the tool for achieving this. Hence, there is need for generous provision of grants for research and publication. Carrying out research and publishing same with meager personal/family funds kills motivation, makes study to become suffering, and also makes room for cutting corners in research design and implementation, which does not help matters in realizing to the fullest, the desired targets of any research initiatives. Hence, there is need for a paradigm shift on the part of those who run both the governments and the academic institutions, both in terms of policy making and implementation, as to guarantee adequate funding for research and publication.

\section{Justification of research}

Evidence shows there has been a considerable rise in the incidence of renal diseases in Nigeria in the last three decades. A survey by this author (unpublished) showed there was a 265\% rise between 1984 and 1993 based on records from the University of Nigeria Teaching Hospital, Enugu, Nigeria, and that trend has remained consistently so ever since then. Though factors responsible for this rising trend has not been clearly documented, known risk factors for renal disease such as hypertension, diabetes mellitus, drugs, food poisoning and other environmentally-related toxicities, as well as urinary tract infections affect significant proportion of our population.

Because most times UTIs are asymptomatic and mild in nature, they are often underrated and overlooked, and in most cases, they will progress to renal diseases. And just like asymptomatic UTIs, some renal diseases (e.g. chronic renal failure) are symptomless until the disease has reached advanced stage, thus making their victims easily vulnerable to sundry complications before actual diagnosis of renal disease may be established. Thus, being prelude to renal diseases, it follows that an early diagnosis and treatment of UTI would help stop possible progressions and developments of the more life-threatening renal diseases. Presently, the contribution of UTI to the renal disease burden of our land is not yet very clearly documented, and the need for such information is very urgent, given the menace of these diseases in our land today. Here lies the justification for the present study aimed at establishing the incidence and identity of the causal organisms of UTI in renal disease of our environment, using the renal disease patients of the University of Nigeria Teaching Hospital, Enugu, Nigeria as a case study. The choice of this hospital is also justified by the fact that, being among the first generation teaching hospitals in Nigeria, and with a good blend of various expertise, including availability of a functional renal centre, it has a vintage location at the centre of the south eastern Nigeria, and therefore remains a major referral tertiary hospital for parts of Nigeria, especially the south eastern and some middle belt states.

\section{Conclusion}

The study revealed an overall incidence of $28 \%$ bacteriuria among renal patients of the University of Nigeria Teaching Hospital Enugu. Though urinary tract infections by sundry microorganisms including Escherichia coli, Klebsiella spp, Proteus mirabilis, Pseudomonas aeruginosa, Streptococcus faecalis, Staphylococcus aureus, Staphylococcus epidermidis and fungal yeast cells (Candida albicans) made reasonable contributions to the renal disease load, adoption of leucocytes presence in urine(pyuria) as part of the diagnostic criteria for UTI revealed that the actual number of UTI cases is likely to be higher than actually established using positive urine culture alone. Additional evidence from urinalysis, revealing proteinuria, haematuria and glycosuria, among others, indicated that, in addition to the contributions by UTIs, diabetes mellitus and/or other diseases or conditions including possibly urinary schistosomiasis (perhaps accounting for the haematuria, though not exclusively), are part of the diseases complex defined by other yet-to-be identified factors inherent in our environment (acting singly or synergistically) that may be playing some key roles in determining or complicating the burdens and patterns of renal diseases in Nigeria. Those other factors need to be properly investigated and established.

\section{Acknowledgement}

The authorities of the Medical Department, University of Nigerian teaching hospital, Enugu are hereby appreciated for permitting this study and allowing uninhibited access to the medical records of their patients. The records aided the observation of a rising renal diseases trend in Nigeria. The doctors and nurses in the medical wards of this hospital are also appreciated for allowing me access to the patients, which helped out immensely in the collection of samples.

\section{References}

1. Asinobi AO, Ademola AD, Ogunkunle OO, Mott SA (2014) Paediatric end-stage renal disease in a tertiary hospital in South West Nigeria. BMC Nephrol 15: 25.

2. Ugwu GI, Nwajei G, Chinemelu U (2014) Pattern of Renal Diseases among Children in The Niger Delta Region, Nigeria. Arab J Nephrol Transplant 7: 49-50.

3. Aneke JC, Adegoke AO, Oyekunle AA, Osho PO, Sanusi AA, et al. (2014) Degrees of kidney disease in nigerian adults with sickle-cell disease. Med Princ Pract 23: 271-274.

4. Okafor UH, Ahmed S, Unuigbe EI (2015) Screening for risk factors of chronic kidney disease in a community in Niger Delta Nigeria. Ann Afr Med 14: 137-142.

5. Hsiao CY, Lin HL, Lin YK, Chen CW, Cheng YC, et al. (2014) Urinary tract infection in patients with chronic kidney disease. Turk J Med Sci 44: 145-149.

6. Wanigasuriya K (2014) Update on uncertain etiology of chronic kidney disease in Sri Lanka's north-central dry zone. MEDICC Rev 16: 61-65.

7. Roberts KB (2014) Urinary tract infections and renal damage: focusing on what matters. JAMA Pediatr 168: 884-885.

8. (1979) Recommended terminology of urinary-tract infection. A report by the members of the Medical Research Council Bacteriuria Committee. Br Med J 2: 717-719.

9. Nerurkar A, Solanky P, Naik SS (2012) Bacterial pathogens in urinary tract infection and antibiotic susceptibility pattern. J Pharm Biomed Sci 21: 1-3.

10. Kunin CM (1979) Detection, prevention and management of urinary tract infection. Lea and Fabiger publishers, Philadelphia. 
11. Gastmeier P, Kampf G, Wischnewski N, Hauer T, Schulgen G, et al. (1998) Prevalence of nosocomial infections in representative German hospitals. J Hosp Infect 38: 37-49.

12. Ronald AR, Nicolle LE, Stamm E, Krieger J, Warren J, et al. (2001) Urinary tract infection in adults: research priorities and strategies. Int J Antimicrob Agents 17: 343-348.

13. Barisić Z, Babić-Erceg A, Borzić E, Zoranić V, Kaliterna V, et al. (2003) Urinary tract infections in South Croatia: aetiology and antimicrobial resistance. Int J Antimicrob Agents 22 Suppl 2: 61-64.

14. American Association of Clinical Chemists (2013) Urinary Tract Infections. AACC.

15. National Kidney and Urologic Diseases Information Clearinghouse (2012) Urinary Tract Infections in Adults. NKUDIC.

16. Anonymous (2013) Can Urinary Tract Infection Lead to Kidney Failure?

17. Ezechi OC, Gab-Okafor CV, Oladele DA, Kalejaiye OO, Oke BO, et al. (2013) Prevalence and risk factors of asymptomatic bacteriuria among pregnant Nigerians infected with HIV. J Matern Fetal Neonatal Med 26: 402-406.

18. Shakya R, Amatya R, Karki BM, Mandal PK, Shrestha KK (2014) Spectrum of bacterial pathogens and their antibiogram from cases of urinary tract infection among renal disorder patients. Nepal Med Coll J 16: 75-79.

19. Osawa K, Shigemura K, Yoshida H, Fujisawa M, Arakawa S (2013) Candida urinary tract infection and Candida species susceptibilities to antifungal agents. J Antibiot (Tokyo) 66: 651-654.

20. Chen YH, Ko WC, Hsueh PR (2013) Emerging resistance problems and future perspectives in pharmacotherapy for complicated urinary tract infections. Expert Opin Pharmacother 14: 587-596.

21. Foxman B (2002) Epidemiology of urinary tract infections: incidence, morbidity, and economic costs. Am J Med 113 Suppl 1A: 5S-13S.

22. Yu S, Fu AZ, Qiu Y, Engel SS, Shankar R, et al. (2014) Disease burden of urinary tract infections among type 2 diabetes mellitus patients in the U.S. J Diabetes Complications 28: 621-626.

23. Orenstein R, Wong ES (1999) Urinary tract infections in adults. Am Fam Physician 59: 1225-123, 1237.

24. Patton JP, Nash DB, Abrutyn E (1991) Urinary tract infection: economic considerations. Med Clin North Am 75: 495-513.

25. Nicolle LE1 (2002) Urinary tract infection: traditional pharmacologic therapies. Am J Med 113 Suppl 1A: 35S-44S.

26. Hooton TM, Scholes D, Hughes JP, Winter C, Roberts PL, et al. (1996) A prospective study of risk factors for symptomatic urinary tract infection in young women. $\mathrm{N}$ Engl J Med 335: 468-474.

27. Ronald A (2002) The etiology of urinary tract infection: traditional and emerging pathogens. Am J Med 113 Suppl 1A: 14S-19S

28. Akerele J, Abhulimen P, Okonofua F (2001) Prevalence of asymptomatic bacteriuria among pregnant women in Benin City, Nigeria. J Obstet Gynaecol 21: 141-144.

29. Akinbami AA, Ajibola S, Bode-Shojobi I, Oshinaike O, Adediran A, et al. (2014) Prevalence of significant bacteriuria among symptomatic and asymptomatic homozygous sickle cell disease patients in a tertiary hospital in Lagos, Nigeria. Niger J Clin Pract 17: 163-167.

30. Khan FG, Ahmed E (2015) Acute renal failure in diabetes mellitus. J Pak Med Assoc 65: 179-182.

31. Ako-Nai KA, Ebhodaghe BI, Osho P, Adejuyigbe E, Adeyemi FM, et al. (2014) Preponderance of bacterial isolates in urine of HIV-positive malaria-infected pregnant women with urinary tract infection. J Infect Dev Ctries 8: 1591-1600.

32. Lee JR, Bang H, Dadhania D, Hartono C, Aull MJ, Satlin M, August P, Suthanthiran M, Muthukumar T (2013) Independent risk factors for urinary tract infection and for subsequent bacteremia or acute cellular rejection: a single-center report of 1166 kidney allograft recipients. Transplantation 96: 732-738.

33. Murphy CN, Mortensen MS, Krogfelt KA, Clegg S (2013) Role of Klebsiella pneumoniae type 1 and type 3 fimbriae in colonizing silicone tubes implanted into the bladders of mice as a model of catheterassociated urinary tract infections. Infect Immun 81: 3009-3017.

34. Puntis D, Malik S, Saravanan V, Rynne M, Heycock C, et al. (2013) Urinary tract infections in patients with rheumatoid arthritis. Clin Rheumatol 32: 355-360.

35. Reisner A, Maierl M, Jörger M, Krause R, Berger D, et al. (2014) Type 1 fimbriae contribute to catheter-associated urinary tract infections caused by Escherichia coli. J Bacteriol 196: 931-939.

36. Zhang Z, Liao L (2014) Risk factors predicting upper urinary tract deterioration in patients with spinal cord injury: a prospective study. Spinal Cord 52: 468-471.

37. Chaudhry R, Madden-Fuentes RJ, Ortiz TK, Balsara Z, Tang Y, et al. (2014) Inflammatory response to Escherichia coli urinary tract infection in the neurogenic bladder of the spinal cord injured host. J Urol 191: 1454-1461.

38. Lomberg H, Hellström M, Jodal U, Leffler H, Lincoln K, et al. (1984) Virulence-associated traits in Escherichia coli causing first and recurrent episodes of urinary tract infections in children with and without vesicoureteral reflux. J Infect Dis 150: 561-569.

39. Tsai YC, Hsu CY, Lin GJ, Wang CJ, Cheng CH, et al. (2004) Vesicoureteral reflux in hospitalized children with urinary tract infection: the clinical value of pelvic ectasia on renal ultrasound, inflammatory responses and demographic data. Chang Gung Med J 27: 436-442.

40. Baracco R, Mattoo TK (2014) Diagnosis and management of urinary tract infection and vesicoureteral reflux in the neonate. Clin Perinatol 41: 633-642.

41. Bayram MT, Kavukcu S, Alaygut D, Soylu A, Cakmakc1 H (2014) Place of ultrasonography in predicting vesicoureteral reflux in patients with mild renal scarring. Urology 83: 904-908.

42. Roupakias S, Sinopidis X, Karatza A, Varvarigou A (2014) Predictive risk factors in childhood urinary tract infection, vesicoureteral reflux, and renal scarring management. Clin Pediatr (Phila) 53: 1119-1133.

43. Akporiaye LE, Aisuodionoe-Shadrach OI (2013) Lower urinary tract pathology evaluation in Nigeria: practice and limitations at a private urology centre. West Afr J Med 32: 216-219.

44. Lien YC, Wang JY, Lee MC, Shu CC, Chen HY, et al. (2013) Urinary tuberculosis is associated with the development of urothelial carcinoma but not renal cell carcinoma: a nationwide cohort study in Taiwan. Br J Cancer 109: 2933-2940.

45. Zisman AL, Evan AP, Coe FL, Worcester EM (2015) Do kidney stone formers have a kidney disease? Kidney Int 88: 1240-1249.

46. Bentall A, Neil D, Sharif A, Ball S (2015) ABO-incompatible kidney transplantation is a novel risk factor for BK nephropathy. Transplantation 99: e8-9.

47. Camargo LF, Esteves AB, Ulisses LR, Rivelli GG, Mazzali M (2014) Urinary tract infection in renal transplant recipients: incidence, risk factors, and impact on graft function. Transplant Proc 46: 1757-1759.

48. Kwon YE, Kim H, Oh HJ, Park JT, Han SH, et al. (2015) Vitamin D deficiency is an independent risk factor for urinary tract infections after renal transplants. Medicine (Baltimore) 94: e594.

49. Kline KA, Schwartz DJ, Gilbert NM, Lewis AL (2014) Impact of host age and parity on susceptibility to severe urinary tract infection in a murine model. PLoS One 9: e97798.

50. Ossai OP, Dankoli R, Nwodo C, Tukur D, Nsubuga P, et al. (2014) Bacteriuria and urinary schistosomiasis in primary school children in rural communities in Enugu State, Nigeria, 2012. Pan Afr Med J 18 Suppl 1: 15 .

51. Ivoke N, Ivoke ON, Nwani CD, Ekeh FN, Asogwa CN, et al. (2014) Prevalence and transmission dynamics of Schistosoma haematobium infection in a rural community of southwestern Ebonyi State, Nigeria. Trop Biomed 31: 77-88.

52. Amuta EU, Houmsou RS (2014) Prevalence, intensity of infection and risk factors of urinary schistosomiasis in pre-school and school aged children in Guma Local Government Area, Nigeria. Asian Pac J Trop Med 7: 34-39. 
53. Morenikeji O, Quazim J, Omoregie C, Hassan A, Nwuba R, et al. (2014) A cross-sectional study on urogenital schistosomiasis in children; haematuria and proteinuria as diagnostic indicators in an endemic rural area of Nigeria. Afr Health Sci 14: 390-396.

54. Ibeneme CA, Oguonu T, Okafor HU, Ikefuna AN, Ozumba UC (2014) Urinary tract infection in febrile under five children in Enugu, South Eastern Nigeria. Niger J Clin Pract 17: 624-628.

55. Hummers-Pradier E, Kochen MM (2002) Urinary tract infections in adult general practice patients. Br J Gen Pract 52: 752-761.

56. Whiteside SA, Razvi H, Dave S, Reid G, Burton JP (2015) The microbiome of the urinary tract--a role beyond infection. Nat Rev Urol 12: 81-90.

57. Lüthje P, Brauner A (2014) Virulence factors of uropathogenic E. coli and their interaction with the host. Adv Microb Physiol 65: 337-372.

58. Nwokocha A, Ujunwa F, Onukwuli V, Okafor H, Onyemelukwe N (2014) Changing Pattern of Bacteriuria among Asymptomatic Secondary School Adolescents within Enugu South East Nigeria. Ann Med Health Sci Res 4: 728-732.

59. Tuerlinckx D, Roelants V, de Bilderling G, Bodart E (1999) [Urinary infection in the child: diagnosis, treatment, and prognosis]. Rev Med Liege 54: 618-622.

60. Jacobson HR (2002) Chronic renal failure: Pathophysiology. Lancet 33: 419-423.

61. Scheffer J, König W, Hacker J, Goebel W (1985) Bacterial adherence and hemolysin production from Escherichia coli induces histamine and leukotriene release from various cells. Infect Immun 50: 271-278.

62. Sobel JD, Reinhart H (1991) Antibacterial host factors in the urinary tract. Adv Intern Med 36: 131-150.

63. Schaeffer AJ, Amundsen SK, Schmidt LN (1979) Adherence of Escherichia coli to human urinary tract epithelial cells. Infect Immun 24: 753-759.

64. Rozalski A (2002) Molecular basis of the pathogenecity of the Proteus bacteria. Advan Clin Experim Med 11: 3-18.

65. Singer RS (2015) Urinary tract infections attributed to diverse ExPEC strains in food animals: evidence and data gaps. Front Microbiol 6: 28.

66. Bala A, Chhibber S, Harjai K (2014) Pseudomonas quinolone signalling system: a component of quorum sensing cascade is a crucial player in the acute urinary tract infection caused by Pseudomonas aeruginosa. Int J Med Microbiol 304: 1199-1208.

67. Johnson JR, Russo TA, Drawz SM, Clabots C, Olson R, et al. (2013) OxyR contributes to the virulence of a Clonal Group A Escherichia coli strain (O17:K+:H18) in animal models of urinary tract infection, subcutaneous infection, and systemic sepsis. Microb Pathog 64: 1-5.

68. He XL, Wang Q, Peng L, Qu YR, Puthiyakunnon S, et al. (2015) Role of uropathogenic Escherichia coli outer membrane protein $\mathrm{T}$ in pathogenesis of urinary tract infection. Pathog Dis 73 .

69. Walser M (2000) Progression of chronic renal failure in man. Kid Intern 37: 195-210.

70. Holmegren K, Danielson BG, Fellstrom B (1999) Infection-induced urinary calculi and renal failure. Scan J Urol 21: 219-233.

71. Bunting-Early T, Figueroa TE (2015) Risk model for renal scarring: validation and implications still needed for primary care practice. JAMA Pediatr 169: 189.

72. Shaikh N, Craig JC, Shope TR (2015) Risk model for renal scarring: validation and implications still needed for primary care-reply. JAMA Pediatr 169: 189-190.

73. Okere P, Ezeofor SN, Iloanusi NI, Ibinaiye PO, Okoye IJ (2015) Sonographic analysis of adult polycystic kidney disease: retrospective data from South-East Nigeria. Niger J Clin Pract 18: 178-182.

74. Ferreiro C, Piepsz A, Nogarède C, Tondeur M, Hainaut M, et al. (2013) Late renal sequelae in intravenously treated complicated urinary tract infection. Eur J Pediatr 172: 1243-1248.

75. Supavekin S, Surapaitoolkorn W, Pravisithikul N, Kutanavanishapong S, Chiewvit S (2013) The role of DMSA renal scintigraphy in the first episode of urinary tract infection in childhood. Ann Nucl Med 27: 170-176.

76. Adeyeba OA, Adegoke GO (1986) Urinary tract pathogens common amongst the inhabitants of a state capital, south west Nigeria. Int J Zoonoses 13: 153-157.

77. Beyene G, Tsegaye W (2011) Bacterial uropathogens in urinary tract infection and antibiotic susceptibility pattern in Jimma university hospital, ethiopia. Ethiop J Health Sci 21: 141-146.

78. Alfred AO, Chiedozie I, Martin DU (2013) Pattern of asymptomatic bacteriuria among pregnant women attending an antenatal clinic at a private health facility in Benin, South-South Nigeria. Ann Afr Med 12: 160-164.

79. Otajevwo FD (2013) Urinary tract infection among symptomatic outpatients visiting a tertiary hospital based in midwestern Nigeria. Glob J Health Sci 5: 187-199.

80. Parameswarappa J, Basavaraj VP, Basavaraj CM (2013) Isolation, identification, and antibiogram of enterococci isolated from patients with urinary tract infection. Ann Afr Med 12: 176-181.

81. Shaikh N, Craig JC, Rovers MM, Da Dalt L, Gardikis S, et al. (2014) Identification of children and adolescents at risk for renal scarring after a first urinary tract infection: a meta-analysis with individual patient data. JAMA Pediatr 168: 893-900.

82. Olorunmola FO, Kolawole DO, Lamikanra A3 (2013) Antibiotic resistance and virulence properties in Escherichia coli strains from cases of urinary tract infections. Afr J Infect Dis 7: 1-7.

83. Stamm WE (2001) An epidemic of urinary tract infections? N Engl J Med 345: 1055-1057.

84. Hooton TM, Stamm WE (1997) Diagnosis and treatment of uncomplicated urinary tract infection. Infect Dis Clin North Am 11: 551-581.

85. Ako-Nai AK, Kassim OO, Adeniran MO, Taiwo O (1993) A study of urinary tract infections at Ile-Ife, Nigeria. East Afr Med J 70: 10-14.

86. Ozumba UC, Dosunmi-Ogunbi O, Onile B (1995) Urinary tract infection with proteus species in a teaching hospital. East Afr Med J 72: 72-74.

87. Padhi S, Dash M, Sahu R, Panda P (2013) Urinary Tract Infection due to Paenibacillus alvei in a Chronic Kidney Disease: A Rare Case Report. J Lab Physicians 5: 133-135.

88. Quirino IG, Dias CS, Vasconcelos MA, Poggiali IV, Gouvea KC, et al. (2014) A predictive model of chronic kidney disease in patients with congenital anomalies of the kidney and urinary tract. Pediatr Nephrol 29: 2357-2364.

89. Saini H, Chhibber S, Harjai K (2015) Azithromycin and ciprofloxacin: A possible synergistic combination against Pseudomonas aeruginosa biofilm-associated urinary tract infections. Int J Antimicrob Agents 45: 359-367.

90. Forbes BA, Sahm DF, Weissfeld AS (2007) Bailey and Scott's Diagnostic microbiology. (12thedn.) Mosby Elsevier, USA.

91. Cowan ST (1974) Cowan and Steel' manual for identification of medical bacteria. (2ndedn.) Cambridge University press, New York.

92. MacFaddin JF (2000) Biochemical tests for identification of medical bacteria. Lippincott Williams and Wilkins, Philadelphia.

93. Finegold SM, Miller LG, Merril SL (1965) Significance of anaerobic and capnophilic bacteria isolate from the urinary tract. In: Kass EH (ed.). Progress in pyelonephritis. F.A Davis co publishers, Philadelphia.

94. Cox CE, Lacy SS, Hinman F Jr (1968) The urethra and its relationship to urinary tract infection. II. The urethral flora of the female with recurrent urinary infection. J Urol 99: 632-638.

95. Strom BL, Collins M, West SL, Kreisberg J, Weller S (1987) Sexual activity, contraceptive use, and other risk factors for symptomatic and asymptomatic bacteriuria. A case-control study. Ann Intern Med 107: 816-823.

96. Bran JL, Levison ME, Kaye D (1972) Entrance of bacteria into the female urinary bladder. N Engl J Med 286: 626-629. 
Citation: Ezejiofor TIN (2016) Environmental Factors in Renal Disease: The Contribution of Urinary Tract Infections in Nigerian Renal Disease Burden-Research and Minireview. Clin Microbiol 5: 237. doi:10.4172/2327-5073.1000237

Page 15 of 15

97. Fihn SD, Johnson C, Pinkstaff C, Stamm WE (1986) Diaphragm use and urinary tract infections: analysis of urodynamic and microbiological factors. J Urol 136: 853-856.

98. Remis RS, Gurwith MJ, Gurwith D, Hargrett-Bean NT, Layde PM (1987) Risk factors for urinary tract infection. Am J Epidemiol 126: 685-694

99. Kahlmeter G1; ECOSENS. (2003) An international survey of the antimicrobial susceptibility of pathogens from uncomplicated urinary tract infections: the ECO.SENS Project. J Antimicrob Chemother 51: 69-76.

100. Grüneberg RN (1969) Relationship of infecting urinary organism to the faecal flora in patients with symptomatic urinary infection. Lancet 2 : 766-768.

101. Schaeffer AJ, Chmiel J (1983) Urethral meatal colonization in the pathogenesis of catheter-associated bacteriuria. J Urol 130: 1096-1099.

102. Svanborg Edén C, Gotschlich EC, Korhonen TK, Leffler H, Schoolnik G (1983) Aspects on structure and function of pili on uropathogenic Escherichia coli. Prog Allergy 33: 189-202.

103. Smith MA, Weingarten RA, Russo LM, Ventura CL, O'Brien AD (2015) Ans against hemolysin and cytotoxic necrotizing factor type 1 (CNF1) reduce bladder inflammation in a mouse model of urinary tract infection with toxigenic uropathogenic Escherichia coli. Infect Immun 83: 1661-1673.

104. Moffet HL (1975) Paediatric Infectious Diseases. J.B Lippincott Co, Philadelphia.

105. Slosky DA, Todd JK (1977) Diagnosis of urinary tract infection. The interpretation of colony counts. Clin Pediatr (Phila) 16: 698-701.
106. Dove GA, Bailey AJ, Gower PE, Roberts AP, De Wardener HE (1972) Diagnosis of urinary-tract infection in general practice. Lancet 2: 1281-1283.

107. Menon S, Kirkendall ES, Nguyen H, Goldstein SL (2014) Acute Kidney Injury Associated with High Nephrotoxic Medication Exposure Leads to Chronic Kidney Disease after 6 Months. J Pediatr 165: 522-527.

108. Small E, Sandefur BJ (2014) Acute renal failure after ingestion of guaifenesin and dextromethorphan. J Emerg Med 47: 26-29.

109. Han SS, Ahn SY, Ryu J, Baek SH, Chin HJ, et al. (2014) Proteinuria and hematuria are associated with acute kidney injury and mortality in critically ill patients: a retrospective observational study. BMC Nephrol 15: 93.

110. Prowle JR, Kolic I, Purdell-Lewis J, Taylor R, Pearse RM, et al. (2014) Serum Creatinine Changes Associated with Critical Illness and Detection of Persistent Renal Dysfunction after AKI. Clin J Am Soc Nephrol 9: 1015-1023.

111. Teschke R, Wolff A, Frenzel C, Schulze J (2014) Review article: Herbal hepatotoxicity--an update on traditional Chinese medicine preparations. Aliment Pharmacol Ther 40: 32-50.

112. Ezejiofor TIN, Ezejiofor AN, Udebuani AC, Ezeji EU, Ayalogbu EA, et al. (2013) Environmental metals pollutants load of a densely populated and heavily industrialized commercial city of Aba, Nigeria. J Toxicol Environ Hlth Sci 5: 1-11. 